\title{
Lipid Peroxide Concentration, Selenium Level, and Glutathione Peroxidase Activity in Blood of Type II (Non-Insulin-Dependent) Diabetic Elderly People
}

\author{
Maria Skkodowska, ${ }^{*}$ Jolanta Gromadziñska, and Wojciech WAsowicz \\ Department of Biochemistry INP WAM, Medical Academy, \\ 90-647 Lódź, Plac 9 Maja 1, Poland
}

(Received March 24, 1989)

\begin{abstract}
Summary The lipid peroxides in terms of malondialdehyde concentration, glutathione peroxidase activity and selenium level were determined in the blood of 22 elderly non-insulin-dependent diabetics of both sexes. The results were compared with the values obtained for 43 healthy persons of the same age. The lipid peroxide concentration in plasma and selenium level in whole blood and plasma were the same in both diabetics and controls. In the diabetes group a nonsignificantly lower (7\%) selenium concentration in red blood cells was observed, whereas the glutathione peroxidase activity in erythrocytes of the patients tested was statistically lower $(p<0.02)$ as compared with normals. In plasma, activity of this enzyme was increased by $14 \%$ as compared with healthy people, but without statistical significance. We found that selenium excretion in the urine found was significantly higher in the diabetics than in healthy people. We found a statistically significant, linear correlation $(r=0.435$, $p<0.05)$ between enzyme activity and lipid peroxide concentration in plasma, and between plasma and urine selenium levels $(r=0.937$, $p<0.001)$ in diabetes.
\end{abstract}

Key Words: lipid peroxides, glutathione peroxidase activity, selenium, type II diabetes mellitus

Diabetes mellitus is a metabolic disorder characterized by high blood glucose level. Two general types of diabetes mellitus are recognized: type I (totally dependent on exogenous insulin), while type II patients can be treated with dietary changes and/or medication [1]. In diabetics other health problems such as renal failure, coronary heart disease, infection and atheriosclerosis are seen [1]. Recent-

*To whom correspondence should be addressed. 
ly, oxygen free radicals have been implicated in this disease [1-3].

An increased level of peroxidized lipids is observed during aging of organisms $[4,5]$, and a higher concentration of these compounds has been found in many human illnesses such as neoplasia, cardiovascular, neurological, or hepatic diseases, cataract, and diabetes [6-9].

Glutathione peroxidase (GSH-Px, EC 1.11.1.9, glutathione: $\mathrm{H}_{2} \mathrm{O}_{2}$ oxidoreductase) is the enzyme known that catalyses the decomposition of $\mathrm{H}_{2} \mathrm{O}_{2}$ and organic peroxides to water and alcohols, respectively, and thus protects cell membranes against peroxidative damage [10]. GSH-Px is a selenoenzyme whose activity is closely dependent upon the concentration of this trace element in the organism $[11,12]$. Selenium $(\mathrm{Se})$ belongs to the group of strong antioxidants in the cell, and its concentration in tissues depends upon daily intake $[13,14]$. As we recently demonstrated [15], blood Se concentrations for adults decrease after 60 years of age, with a simultaneous decrease in GSH-Px activity and increase in lipid peroxide concentration in blood plasma [Gromadzińska, J. et al., unpublished results]. Further, it has been shown $[16,17]$ that deficiency of Se in the body causes a decrease of GSH-Px activity that may result in accumulation of toxic peroxides in the cell.

Few works, however, have been published on the role played by lipid peroxides $[1-3,18,19]$ and Se $[20,21]$ as well as GSH-Px $[2,3,19,22]$ in type II diabetic patients, and results obtained are often controversial. The present study was undertaken to evaluate the interrelationship between lipid peroxide level, GSH-Px activity, and Se concentrations in blood of type II diabetic (non-insulindependent) elderly people, in view of the protective role against tissue damage that has been ascribed to the GSH-Px/Se system [23]. Since the determination of Se level in urine may indicate its level in the organism [24], we also examined Se excretion in the urine of the tested patients.

\section{MATERIAL AND METHODS}

Twenty-two diabetes patients (non-insulin-dependent) aged 51-80 years (12 men and 10 women) were tested. The patients were under routine medical care and were treated with a standard diet and received insulin injections ( 8 persons) or oral antidiabetic agents of sulphonylurea type (14 persons). Patients taking glutathione, vitamins $\mathrm{C}$ and $\mathrm{E}$, as well as coenzyme $\mathrm{Q}$, were excluded. The control group consisted of 43 clinically healthy persons aged 63-97 years (21 men and 22 women).

Venous blood was taken into heparinized tubes free of trace elements, after an overnight fast. Whole blood (WB) was separated into blood plasma and erythrocytes $(\mathrm{RBC})$ by centrifugation at $4^{\circ} \mathrm{C}$ and $3,000 \times g$ for $10 \mathrm{~min}$ in isotonic solution of sodium chloride. The lysates of $\mathrm{RBC}$ were prepared by freezing and thawing three times, and centrifuged at $1,500 \times g$ for $15 \mathrm{~min}$ at $4^{\circ} \mathrm{C}$ in order to remove membranes. Haemoglobin $(\mathrm{Hb})$ content of $\mathrm{WB}$ and haemolysates was 
estimated according to the cyanomethaemoglobin method of Drabkin. Haematocrit was also determined. The protein content in plasma was measured by the method of Lowry et al. [25].

Lipid peroxides were measured in blood plasma by the fluorometric methods using thiobarbituric acid (TBA) as described by Yagi [26]. Lipids contained in plasma were precipitated with phosphotungstic acid, followed by the reaction with TBA. The reaction product was measured fluorometrically and the lipid peroxide concentrations were expressed in terms of malondialdehyde, in $\mathrm{nmol} / \mathrm{ml}$ of plasma.

The GSH-Px activity of the red-cell haemolysates and plasma was assayed using the Hopkins and Thudhope modification [27] of the coupled-enzyme assay of Paglia and Valentine [28], with $t$-butyl-hydroperoxide as the acceptor of substrate.

Se concentration in WB, plasma, and urine was determined fluorometrically by the method of Watkinson [29], using 2,3-diaminonaphthalene as the complexing reagent. Quality control was monitored by the use of the International Atomic Energy Agency dried animal blood standard (A-13) [15]. The Se concentration in the RBC was calculated from the difference between Se content in WB and that in plasma [12] with allowance made for the haematocrit. Se concentration in WB, $\mathrm{RBC}$ and plasma were expressed in $\mu \mathrm{g} /$ liter while urine selenium levels are expressed in $\mu \mathrm{g} \mathrm{Se} / \mathrm{g}$ of creatinine (CT). CT levels in urine samples were determined by the method of Folin and $\mathrm{Wu}$ [30].

The data obtained were used to calculate means, standard deviations, and linear correlation coefficient. Statistical significance was analyzed by Student's $t$-test. Differences at $p<0.05$ were considered significant.

\section{RESULTS}

The results obtained are presented in Tables 1 and 2. We found that both lipid peroxide concentration in plasma and Se levels in WB and plasma in diabetes did not differ from those of the control group. In the diabetes group a nonsignificantly lower Se concentration in RBC was observed as compared with the healthy people.

The GSH-Px activity in RBC of the tested patients was significantly depressed $(p<0.02)$, while in plasma the activity of the enzyme was higher by $14 \%$, but without statistical significance. A positive, statistically significant linear correlation $(r=0.434 ; p<0.05)$ was found between lipid peroxide concentration and GSH-Px activity in plasma of diabetes patients. We found that Se urinary excretion in diabetes was significantly higher than that found in the healthy people $(p<0.0001)$. Patients treated with insulin had significantly higher $(p<0.006)$ GSH-Px activity in their RBC as compared with the group receiving oral drugs (Table 2). Se concentration in blood plasma of patients receiving insulin was found to be $84 \pm 16 \mu \mathrm{g} /$ liter as compared with the value $69 \pm 16 \mu \mathrm{g} /$ liter obtained in patients receiving oral drugs $(p<0.05)$. The concentration of Se excreted in the

Vol. 7, No. 1, 1989 
Table 1. Lipid peroxide concentration, glutathione peroxidase activity, and Se level in blood and/or urine in non-insulin-dependent elderly people.

\begin{tabular}{lcc}
\hline Parameters & $\begin{array}{c}\text { Control subjects } \\
(n=43)\end{array}$ & $\begin{array}{c}\text { Diabetic patients } \\
(n=22)\end{array}$ \\
\hline Lipid peroxides $(\mathrm{nmol} / \mathrm{ml})$ & $4.38 \pm 1.22$ & $4.25 \pm 0.71$ \\
GSH-Px activity $(\mathrm{U} / \mathrm{g} \mathrm{Hb} \mathrm{RBC})$ & $16.7 \pm 2.6$ & $14.2 \pm 4.4^{*}$ \\
GSH-Px activity $(\mathrm{U} / \mathrm{ml}$ plasma) & $0.202 \pm 0.036$ & $0.231 \pm 0.033$ \\
WB Se $(\mu \mathrm{g} /$ liter $)$ & $97 \pm 22$ & $96 \pm 21$ \\
$\mathrm{RBC} \mathrm{Se}(\mu \mathrm{g} / \mathrm{liter}$ packed cells) & $133 \pm 36$ & $124 \pm 31$ \\
Plasma Se $(\mu \mathrm{g} /$ liter $)$ & $72 \pm 18$ & $74 \pm 18$ \\
Urine Se $(\mu \mathrm{g} / \mathrm{g} \mathrm{CT})$ & $14.8 \pm 5.6$ & $23.2 \pm 6.9^{* *}$ \\
\hline
\end{tabular}

Mean \pm SD. Significant difference in comparison with control group: ${ }^{*} p<0.02,{ }^{* *} p<0.0001$.

Table 2. Lipid peroxide concentration, glutathione peroxidase activity and Se level in blood and/or urine in non-insulin-dependent diabetic receiving insulin and oral drugs.

\begin{tabular}{lcc}
\hline & \multicolumn{2}{c}{ Diabetes } \\
\cline { 2 - 3 } Parameters & $\begin{array}{c}\text { Group receiving insulin } \\
(n=8)\end{array}$ & $\begin{array}{c}\text { Group receiving oral drugs } \\
(n=14)\end{array}$ \\
\hline Lipid peroxides $(\mathrm{nmol} / \mathrm{ml})$ & $4.41 \pm 0.67$ & $4.16 \pm 0.75$ \\
GSH-Px activity $(\mathrm{U} / \mathrm{g} \mathrm{Hb} \mathrm{RBC})$ & $18.1 \pm 4.8$ & $12.3 \pm 2.8^{*}$ \\
GSH-Px activity $(\mathrm{U} / \mathrm{ml}$ plasma) & $0.242 \pm 0.025$ & $0.226 \pm 0.036$ \\
WB Se $(\mu \mathrm{g} /$ liter $)$ & $107 \pm 19$ & $90 \pm 21$ \\
RBC Se $(\mu \mathrm{g} /$ liter packed cell) & $133 \pm 26$ & $119 \pm 34$ \\
Plasma Se $(\mu \mathrm{g} /$ liter $)$ & $84 \pm 16$ & $69 \pm 16^{* *}$ \\
Urine Se $(\mu \mathrm{g} / \mathrm{g} \mathrm{CT})$ & $43.4 \pm 24.2$ & $9.5 \pm 3.6^{* * *}$ \\
\hline Mean $\pm \mathrm{SD}$. Significant difference in comparison with control group: ${ }^{*} p<0.006,{ }^{* *} p<0.005$, \\
$* * * p<0.003$.
\end{tabular}

urine was significantly higher $(p<0.003)$ in patients receiving insulin (Table 2$)$.

In the case of type II diabetic patients, we have found a strong linear correlation between Se concentration in plasma and that in urine $(r=0.937 ; p<0.001)$, while for normals this correlation was weaker $(r=0.543)$.

\section{DISCUSSION}

Patients with type II diabetes and angiopathy had more thiobarbituric acidreactive material than controls, while patients without angiopathy did not exhibit such increase [31]. In our research we found that the lipid peroxide concentration was similar both in diabetic and control groups. The patients examined by us were under constant medical care, and underwent regular check-ups. This discrepancy is understandable in view of the observations by Sato et al. [18], who pointed out that lipid peroxide concentration was increased $61 \%$ in adult subjects with poorly controlled type diabetes, but unchanged in patients with well controlled diabetes. 
In one study, GSH-Px activity in RBC of type II diabetics was increased [2], but was decreased in another study [3], or showed no change in yet another study [19]. We demonstrated that GSH-Px activity is significantly depressed in diabetic patients (Table 1). Hagloff et al. [32] also observed that GSH-Px activity in erythrocytes of children with insulin-dependent diabetes mellitus was lower, but the deviation from the control was small. Michaelson [22] found a decrease in GSH-Px activity in RBC of diabetic patients.

In diabetic patients serum Se levels have been reported to be normal [20] or even higher than in healthy, age-matched controls [29]. In children this may be explained by the specific diet recommended for diabetic patients [21,33]. In our study we have determined not only the plasma Se concentration but also that of whole blood and of erythrocytes, and demonstrated that the concentrations of the element in various blood compartments (WB, RBC, and plasma) did not show statistically significant differences between diabetic patients and controls. However, we did find a statistically lower Se concentration in blood plasma of patients receiving oral drugs as compared with those who received only insulin (Table 2).

Diabetes is a general term referring to disorders characterized by an excessive urinary excretion of glucose. As was pointed out by Wasowicz et al. [15], the concentration of Se excreted in the urine correlates with both the concentration of the element in whole blood and that in blood plasma. The results obtained in our present study indicate an increased Se excretion in urine of diabetes (Table 1) and they call attention to the fact that the concentration of the element in urine of patients receiving insulin is 3 times higher than in urine of healthy people (Table 2). The demonstrated linear correlation between Se content in blood plasma and its concentration in urine suggests that the Se content in urine is a useful indicator of this microelement status in the organism.

The explanation of the observed significantly higher GSH-Px activity in red blood cells and increased excretion of Se with urine in patients treated with insulin as compared with those receiving oral drugs (Table 2) requires further, more thorough investigation.

\section{REFERENCES}

1. Oberley, W.O. (1988): Free radicals and diabetes. Free Radical Biol. Med., 5, 113-124.

2. Matkovics, B., Varga, S.I., Szabo, L., and Witas, H. (1982): The effect of diabetes on the activities of the peroxide metabolism enzymes. Horm. Metab. Res., 14, 77-79.

3. Uzel, N., Sivas, A., Uysal, M., and Oz, H. (1987): Erythrocyte lipid peroxidation and glutathione peroxidase activities in patients with diabetes mellitus. Horm. Metab. Res., 19, $89-90$.

4. Nohl, H., and Hegner, D. (1979): Responses of mitochondrial superoxide dismutase, catalase and glutathione peroxidase activities to aging. Mech. Ageing Dev., 11, 145-151.

5. Vericel, E., Lagarde, M., Dechavanne, M., and Curpron, P. (1985): Increased lipid peroxidation in platelets from elderly people. Thromb. Haemost., 54, 553.

6. Anderson, R.E., Rapp, L.M., and Wiegand, R.D. (1984): Lipid peroxidation and retinal degradation. Curr. Eye Res., 3, 223-227.

Vol. 7, No. 1, 1989 
7. Dousset, J.C., Trouihl, M., and Foglietli, M.J. (1984): Plasma malondialdehyde levels during myocardial infarction. Clin. Chim. Acta, 129, 319-322.

8. Shamberger, R.J., Andreone, T.L., and Willis, Ch.E. (1974): Antioxidants and cancer IV. Initiating activity of malondialdehyde as a carcinogen. J. Natl. Cancer Inst., 53, 1771-1773.

9. Yagi, K. (1984): Increased serum lipid peroxides initiate atherogenesis. BioEssays, 1, 58-61.

10. Tappel, A.L. (1978): Protection against free radical lipid peroxidation reactions. Adv. Exp. Med. Biol., 97, 111-131.

11. Smith, P.J., Tappel, A.L., and Chow, C.K. (1974): Glutathione peroxidase activity as a function of dietary selenomethionine. Nature, 247, 392-394.

12. Thompson, U.G., Fraser, A.J., Harrop, B.H., and Kirk, I.A. (1980): Glutathione peroxidase in bovine serum and erythrocytes in relation to selenium concentration in blood, serum, and liver. Res. Vet. Sci., 28, 321-324.

13. Valentine, J.L., Kang, H.K., Dang, P.M., and Schluchter, M. (1980): Selenium concentration and glutathione peroxidase activities in a population exposed to selenium via drinking water. J. Toxicol. Environ. Health, 6, 731-736.

14. Burk, R.F. (1974): In vivo Se binding to human plasma proteins after administration of $\mathrm{SeO}$. Biochim. Biophys. Acta, 372, 255-265.

15. Wasowicz, W., and Zachara, B.A. (1987): Selenium in the blood and urine of a healthy Polish sub-population. J. Clin. Chem. Clin. Biochem., 25, 409-412.

16. Spooner, R.J., Campbell, R.A., Rumley, A.G., and Stromberg;, P. (1980): Glutathione peroxidase in human selenium deficiency. Proc. Nutr. Soc., 39, 93.

17. Dianzani, M.U. (1982): Biochemical effects of saturated and unsaturated aldehydes, in Free Radicals, Lipid Peroxidation and Cancer, ed. by Slater, D.C.H., Academic Press, London, p. 129.

18. Sato, Y., Hotta, N., Sakamoto, N., Matsuoka, S., Ohishi, N., and Yagi, K. (1979): Lipid peroxide levels in plasma of diabetic patients. Biochem. Med., 21, 104-107.

19. Kaji, H., Kurasaki, M., Ito, K., Saito, K., and Niioka, T. (1985): Increased lipoperoxide value and glutathione peroxidase activity in blood plasma of type II (non-insulindependent) diabetic women. Klin. Wochenschr., 63, 765-768.

20. Burk, R.F. (1980): Selenium in man, in Trace Elements in Human Health and Disease, ed. by Prasad, A.S., Academic Press, New York, pp. 105-133.

21. Gebre-Medhin, M., Ewald, U., Plantin, L.O., and Tuvemo, T. (1984): Elevated serum selenium in diabetic children. Acta Paediatr. Scand., 73, 109-114.

22. Michaelson, A.M. (1982): Clinical use of superoxide dismutase and possible pharmacological approaches, in Pathology of Oxygen, ed. by Autor, A.P., Academic Press, New York, pp. 277-302.

23. Tappel, A.L. (1974): Selenium-Glutathione peroxidase and vitamin E. Am. J. Clin. Nutr., 27, 960-967.

24. Wạsowicz, W., Gołẹbiowska., M., and Chlebna-Sokół, D. (1988): Increased urinary excretion of selenium in children-A response to surplus fluorine in drinking water. Tr. Elem. Med., 5, 43-46.

25. Lowry, O.H., Rosebrough, N.J., Farr, A.L., and Randall, R.J. (1951): Protein measurement with the folin-phenol reagent. J. Biol. Chem., 193, 265-275.

26. Yagi, K. (1976): A simple fluorometric assay for lipoperoxide in blood plasma. Biochem. Med., 15, 212-216.

27. Hopkins, J., and Thudhope, G.R. (1973): Glutathione peroxidase in human red cells in health and disease. Br. J. Haematol., 25, 563-575.

28. Paglia, D.E., and Valentine, W.N. (1967): Studies on quantitative and qualitative characterization of erythrocyte glutathione peroxidase. J. Lab. Clin. Med., 70, 158-169.

29. Watkinson, J.H. (1966): Fluorometric determination of selenium in biological material with 2,3-diaminonaphthalene. Anal. Chem., 38, 92-97.

30. Hawk, P.B., Oser, B.L., and Summerson, W.H. (1947): Practical Physiological Chemistry, The Blakiston Company, Philadelphia, Toront, pp. 506-511. 
31. Hayaishi, O., and Shimizu, T. (1982): Metabolic and functional significance of prostaglandins in lipid peroxide research, in Lipid Peroxides in Biology and Medicine, ed. by Yagi, K., Academic Press, New York, pp. 41-53.

32. Hagloff, B., Marklund, S., and Holmgren, G. (1983): CuZn superoxide dismutase, Mn superoxide dismutase, catalase, and glutathione peroxidase in lymphocytes and erythrocytes in insulin-dependent diabetic children. Acta Endocrinol., 102, 235-239.

33. Makela, A.L., Tasane, M., Lazowska, E., Pulkki, K., Hyora, H., and Nanto, V. (1987): Serum selenium levels and glutathione peroxidase activities in erythrocytes of rheumatic and diabetic children and their families living in Western Finland, in Trace Element-Analytical Chemistry in Medicine and Biology, ed. by Bratter, P., and Schramel, P., Walter de Gruyter, Berlin, New York, Vol. 4, pp. 557-563. 